Naudé, C \& Terblanche, $L S$

\title{
DIE ONTWIKKELING VAN 'N BEMARKINGSTRATEGIE VIR CENTURION GEMEENSKAPSDIENS
}

\author{
Mev Naudé is 'n magisterstudent en prof Terblanche 'n personeellid van die Departement \\ Maatskaplike Werk, Universiteit van Pretoria.
}

\begin{abstract}
Centurion Community Services (CCS), a social service agency situated in Lyttelton,Pretoria, was founded in February 1999. The geographical area where services were rendered over the past four years has been transformed from a once quiet rural scene to a densely populated urban area. The founding of CCS testifies to a pro-active step to address anticipated social problems associated with urbanisation.

A qualitative study was launched with the aim to assess the community's perception concerning CCS and whether this service is able to fulfil the needs and wants of the community with a view of development of guidelines for a consumer-based marketing strategy.
\end{abstract}

A schedule covering the seven critical areas of decision-making in a marketing strategy had been developed and utilised as a data collection instrument to collect data from respondents, who have all been beneficiaries in one way or another of this service.

It was found that a strategic planning process should be implemented in order to obtain clarity regarding the vision and mission of the organization; a marketing plan (which includes the strategic analysis, the SWOT analysis, marketing objectives and marketing strategy) should be applied extensively. A number of recommendations regarding critical decision making areas were also formulated.

\section{INLEIDING EN ORIËNTERING TOT DIE ONDERSOEK}

Centurion Gemeenskapsdiens is 'n nie-staatsgesubsidieerde, nie-winsgerigte maatskaplikewerkdiens wat sedert 1 Februarie 1999 onder beskerming van die NG Gemeente Lyttelton funksioneer. Die bestaan van Centurion Gemeenskapsdiens spruit direk voort uit die besorgdheid en inisiatief van 'n gemeenskapslid na aanleiding van die gesubsidieerde welsynsorganisasies van die 1999-Finansieringsbeleid van die Staat, waarvolgens sodanige organisasies toenemend onder finansiële druk sal verkeer, veral in 'n oënskynlik ontwikkelde gemeenskap.

Dienste word hoofsaaklik binne die geografiese area van dié gemeente gelewer. Die twee maatskaplike werkers (een voltyds en een deeltyds) word deur 'n borg gefinansier. Vakkundige werksaamhede eie aan 'n gesinsorgorganisasie word verrig deur die toepassing van alle metodes van maatskaplike werk. Die fokus is op primêre voorkoming. Gemeenskapsprojekte word dus as 'n hoë prioriteit beskou.

Die geografiese gebied, waarin die NG Gemeente Lyttelton geleë is, het die afgelope vier jaar ongekende uitbreiding beleef. Ongeveer honderd- en- twintig meenthuiskomplekse is op die eertydse landbouhoewes ontwikkel. Die diens is geïnisieer vanuit die pro-aktiewe optrede na aanleiding van die waarneming van demografiese tendense en voortspruitende problematiek soos byvoorbeeld die hoë voorkoms van saamwonery, enkelouerskap, onbeheerbaarheid van tieners, materiële nood en chemiese afhanklikheid, veral ook onder tieners. 
Benewens krisisingryping word bepaalde toerustingskursusse ter ontwikkeling van vaardighede in ouerskap, finansies, die huwelik en die bemagtiging van individue ter voorkoming van chemiese afhanklikheid aangebied. Vakansieprogramme vir laerskoolleerlinge speel ook 'n belangrike rol in die voorkoming, vroeë identifisering en aanspreek van problematiek.

Die inhoud van programme was tot op hede veral gebaseer op die oordeel van die maatskaplike werkers en lede van die vakkundige komitee. Daar is nog geen wetenskaplike ondersoek na die behoeftes van potensiële verbruikers ingestel nie. Na ongeveer vier jaar word die diens nog nie maksimaal benut nie. Dit word bevestig deur die aantal maandelikse aanmeldings, die huidige gevalleladings van die maatskaplike werkers en die maandelikse statistiese gegewens wat 'n weerspieëling is van die maatskaplike werkers se tydsbesteding. Die afleiding kan gemaak word dat pogings om die diens bekend te stel, tot op hede nie effektief was nie en dat die gemeenskap nie voldoende ingelig is oor hoe hulle persoonlik by dienste kan baat nie.

In hierdie verband konstateer Weyers (1999:124) dat die aard van dienslewering dikwels nie verstaan word deur of bekend is aan diegene wat dit die nodigste het nie. Die onkunde van die gemeenskap kan ook toegeskryf word aan maatskaplike werkers se onvoldoende en onwetenskaplike bemarking van die professie en sy dienste wat direk bydra tot wanpersepsies of die stigmatisering van die professie in die algemeen.

Om 'n werklike verskil in lewenskwaliteit te maak, is dit noodsaaklik dat die persone wat die dienste nodig het, weet hoe hulle persoonlik daarby kan baat. Effektiewe bekendstelling (wetenskaplike bemarking) het daarom noodsaaklik geword. Om 'n bemarkingstrategie te ontwikkel, moes daar eers begrip verkry word vir die verbruikers se persepsie en belewenis van die huidige dienslewering en hul behoeftes.

\section{PROBLEEMFORMULERING}

Die navorsers wou daarom deur middel van hierdie studie ondersoek instel na verbruikers se indrukke, belewenisse, kennisvlakke, persepsies, houdings en verwagtinge van die diens omdat dit hul beeld van die organisasie bepaal. Die beeld van 'n organisasie is die somtotaal van oortuigings, idees en indrukke wat mense van 'n program, dienste of produkte het (Wolf, 1990:121). Die beeld wat verbruikers van 'n instelling het, word beïnvloed deur vorige ervarings en sal bepaal of hulle bereid is om met die organisasie te identifiseer en van die dienste gebruik te maak.

Om effektiewe dienslewering te verseker, moet die behoeftes van die teikengemeenskap aangespreek word. In hierdie verband konstateer Crompton en Lamb (1986:3) dat die sosiale en ekonomiese regverdiging vir 'n organisasie se bestaan die bevrediging van “customer wants" is. 'n Organisasie moet met die oë van 'n kliënt of teikenmark kyk en vasstel wat nodig is sodat daarin voorsien kan word. Hierdie gedagte word ondersteun deur Andreasen (1997:5) wat bevestig dat daar voortdurend na die teikenmark teruggegaan moet word. Voor en na die beplanning en implementering moet dus vasgestel word wat hul behoeftes is.

Die vraag ontstaan ook wat dit is wat gemeenskapslede motiveer of beïnvloed in hul besluitneming om die dienste van 'n organisasie te benut of ' $n$ bydrae in terme van hul tyd te maak. Hierin is Wolf (1990:126) van mening dat die volgende vier p's van die "marketing mix" in ag geneem moet word:

- Die produk (insluitend programme en dienste)

- Promosie (van die produk, program of diens- totale kommunikasie met die teikenmark)

- Prys (koste verbonde aan deelname- monetêr en in terme van tyd en opoffering)

- Die plek (waar die produkte, programme en dienste beskikbaar is) 
Ander skrywers maak ook melding van 'n verdere drie kritiese besluitnemingsareas, naamlik die

- Personeel (professionele persone wat die diens verrig)

- "Presentation" (beeld van die organisasie)

- Proses (beoordeling in terme van verbruikersvriendelikheid)

(Cowell, 1991:59-75; Crompton \& Lamb, 1986:22-23; Herbst, 2001:351-352; Weyers, 1999:125)

Die gemeenskapslede se behoeftes moet in ag geneem word in al die elemente van die "marketing mix", hierna genoem die kritiese besluitnemingsareas, om 'n markgerigte diens aan te bied. Programme en dienste moet hiervolgens beplan word anders sal verbruikers se behoeftes nie aangespreek word nie en hulle nie persoonlik daarby baat nie.

Volgens die organisasiebeleid word die ideaal gestel dat $75 \%$ van die tyd van maatskaplike werkers aan direkte dienslewering (vakkundige take) en $25 \%$ aan administrasie en nie-vakkundige werksaamhede bestee word. Gedurende die eerste bestaansjaar is slegs ongeveer $55 \%$ van die beskikbare ure aan direkte dienslewering bestee en die res aan ander take. Hoewel daar tans toenemend meer tyd aan vakkundige dienslewering bestee word, is daar steeds ruimte vir verbetering.

Uit die aard van en die getal aanmeldings kan afgelei word dat die gemeenskap of potensiële kliënte nog nie oor genoegsame kennis aangaande die dienste beskik nie. Die meeste nuwe aanmeldings is verwysings deur gemeentelede, gemeenskapslede of ander professionele persone. In 'n mindere mate soek individue op eie inisiatief hulp. Dit kan uit vrees vir blootstelling wees, maar ook uit onkunde. Maatskaplike werkers is steeds bewus van egpare met huweliksprobleme, egskeidings wat plaasvind, onbeheerbaarheid van tieners en tieners met afhanklikheidsprobleme wat nie aanmeld om professionele hulp te ontvang nie.

Die aard van sekere projekte waarby maatskaplike werkers betrokke is, byvoorbeeld die voedselpakkieprojek, kan die indruk wek dat maatskaplike werkers veral praktiese en materiële nood aanspreek. Terapeutiese betrokkenheid word met konfidensialiteit hanteer, daarom is gemeenskapslede nie noodwendig bewus van die beskikbare terapeutiese kundigheid en dienste nie.

Individue verkeer steeds in krisis en ontbeer vakkundige toetrede, wat 'n verbetering in hul lewenskwaliteit sou kon meebring. Die kennisvlak en behoeftes van verbruikers moet bepaal word. Slegs wanneer hierdie inligting benut en in ' $n$ doelgerigte bemarkingstrategie ontwikkel word, kan bemarking suksesvol wees en die optimale benutting van die diens gewaarborg word. Tot op hede was pogings om die aard en omvang van dienste bekend te stel, nog onsuksesvol. Die vorige oneffektiewe bemarkingspogings is die navorsingsprobleem wat aangespreek moes word.

\section{BEMARKING IN 'N NIE-WINSGERIGTE ORGANISASIE}

Bemarking word tradisioneel met die verhandeling van konkrete produkte verbind. In hierdie ondersoek word bemarking beskou teen die agtergrond van 'n nie-winsgerigte organisasie waarin nie tasbare produkte nie, maar dienste verhandel word.

Nie-winsgerigte organisasies word deur Mayers (1989:8) omskryf as sinoniem met "human service organizations". Voorbeelde van "human service organizations" in die alledaagse lewe is instansies soos skole en universiteite. Vir die doeleindes van hierdie studie word 'n niewinsgerigte "human service organization" beskou as 'n vrywillige privaat organisasie wat primêre 
ten doen het om maatskaplike welsynsdienste te lewer. 'n Sekondêre doel sou wees om winsgerig te wees ten einde verdere programme finansieel moontlik te maak.

'n Geslaagde en effektiewe bemarkingstrategie is noodsaaklik vir die voortbestaan van 'n winsgerigte organisasie en in 'n sekere sin nog belangriker in 'n nie-winsgerigte organisasie. Motivering hiervoor is in die ooreenkomste en verskille tussen die twee groepe organisasies geleë en behels kortliks die volgende (Mayers, 1989:8-10):

- Beide verskaf dienste. Winsgerigte privaat gesinsorg- en huweliksverwante dienste word verskaf aan en benut deur dié wat dit kan bekostig. Ander kliënte is noodgedwonge aangewese op staatsgesubsideerde dienste.

- Beide het goedere en dienste waarvoor verbruikers gewerf moet word. Maatskaplike dienste word dikwels onderbenut omdat gemeenskapslede onbewus daarvan is, dit met 'n stigma assosieer of omdat hulle op hul eie ondersteuningsisteme staatmaak. Diensleweringsorganisasies moet hul dienste so goed as moontlik aan die teikenpopulasie bekend stel, op dieselfde wyse as wat winsgerigte organisasies dit doen. Bemarking behoort daarom hoë prioriteit te wees.

- Beide soorte organisasies benodig arbeid, materiaal en fasiliteite wat finansiële uitgawes verg. Hierdie middele moet befonds word. Winsgerigte organisasies doen dit deur hul winste. Niewinsgerigte organisasies is hier aangewese op borge en ander vorme van skenkings, wat die direkte gevolg van geslaagde bemarking is.

- Beide moet finansieel lewensvatbaar bly. Terwyl winsgerigte organisasies dit vanuit die kapasiteit van winsbejag doen, moet nie-winsgerigte organisasies dit vanuit 'n effektiewe bemarkingstrategie doen.

- Beide winsgerigte en nie-winsgerigte organisasies is aangewese op beperkte hulpbronne en donateurs om wie daar meegeding word. Die noodsaaklikheid van 'n effektiewe bemarkingstrategie word hierdeur benadruk.

- Dienste (produkte van die organisasies) beskik oor unieke eienskappe wat in die bemarking daarvan verreken moet word. Verskeie skrywers bespreek hierdie karakteristieke eienskappe. (Cowell, 1991:23-26; Jooste, 1993:638-642; Kotler \& Andreasen, 1991:390-393.; Kurtz \& Clow, 1998:10-13; Lovelock, 1991:40-41).

\section{Nie-tasbaar}

Dienste is nie-tasbaar en nie met sintuie waarneembaar nie. Die verbruiker moet daarom vertroue in die diensverskaffer hê en sal 'n oordeel vorm op grond van dit wat wel sigbaar is, byvoorbeeld die voorkoms van die personeel, geboue, die indruk van die ontvangslokaal, die kwaliteit van brosjures en byvoorbeeld die inskrywingsvorms vir 'n spesifieke projek.

Omdat dienste onsigbaar is, moet dít wat wel sigbaar is, uitgebou word.

\section{Onskeibaar}

Die produk wat aangebied word, kan nie geskei word van die persoon wat dit aanbied nie. Verbruikers sal personeel se kennis, houding en vaardigheid krities beoordeel. Om dienste as 'n produk aan te bied, word vereis dat die diensverskaffer self teenwoordig moet wees om die diens te verskaf. Kwaliteitkommunikasie met verbruikers in alle fases van verbruik van dienste kan egter meewerk om verbruikerstevredenheid te bevorder. Personeel moet daarom kundig wees en volgens hul vaardighede en belangstellings in die organisasie aangewend word. 


\section{Heterogene kwaliteit}

Omdat die produk nie van die diensverskaffer geskei kan word nie, word die kwaliteit van 'n diens bepaal deur wie dit aanbied. Dit bemoeilik die standaardisering van dienste. Daar is groter druk op organisasies om die beste diens te bied. Dit is dus in die belang van die organisasie dat personeel noukeurig geselekteer word, toepaslike opleiding gegee en effektief gemonitor word (Hannagan, 1992:105).

\section{Verganklikheid}

Dienste wat beskikbaar is, kan nie geberg of gestoor word nie, maar moet benut word wanneer dit beskikbaar is. Indien 'n verbruiker nalaat om 'n afspraak na te kom, kan die diens (produk) nie gelewer word nie en die diensverskaffer se tyd is onbenut.

Permanente personeel moet vergoed word, ongeag of daar op die kort termyn 'n aanvraag na dienste bestaan. Daar behoort 'n beter balans tussen aanvraag en aanbod bewerk te word.

\section{Eienaarskap}

Die gebrek aan eienaarskap van dienste (teenoor eienaarskap van goedere of produkte) word deur Cowell (1991:26) as 'n verdere kenmerk beskryf. 'n Verbruiker het eers toegang tot dienste wanneer dit gebruik word, terwyl 'n produk die eiendom van die verbruiker word selfs nog voordat dit gebruik word. Kwaliteitdienslewering moet daarom nagestreef word.

Uit die voorafgaande blyk dit dat 'n markgerigte benadering tot dienste meebring dat die aanbieding van 'n organisasie se dienste/produkte nie slegs verband hou met die fisiese of konkrete nie, maar met al die unieke eienskappe van dienste (Cowell, 1991:35-36). Hierdie eienskappe word deur die sewe P's (kritiese besluitnemingsareas) ondervang.

\section{NAVORSINGSPROSEDURE EN WERKSWYSE}

\section{Doelstelling en doelwitte}

Die doelstelling vir die studie is:

Om 'n bemarkingstrategie vir Centurion Gemeenskapsdiens te ontwikkel.

Die volgende doelwitte is gestel:

- Om deur middel van 'n literatuurstudie kennis oor die aard van bemarking (veral ten opsigte van die kritiese besluitnemingsareas) in 'n nie-winsgerigte organisasie te verbreed.

- Om deur middel van 'n empiriese ondersoek te verken wat verbruikers/kliënte se persepsie van die aard en omvang van die bestaande dienste is.

- Om vas te stel of verbruikers se behoeftes en verwagtinge deur dienslewering aangespreek word.

- Om die aanbevelings of riglyne wat uit die ondersoek verkry word, in die ontwikkeling van 'n verbruikersgerigte bemarkingstrategie te benut.

\section{Navorsingsaanname vir die studie}

Aangesien daar in hierdie studie van die verkennende ontwerp gebruik gemaak is, is daar nie ' $n$ hipotese aan die begin gestel nie. Fouchè en De Vos (1998:124) gebruik spesifiek die begrip 
"hypothesis-developing design" as sinoniem vir verkennende navorsing. Hulle verwys na: "preexperimental/hypothesis-developing/exploratory designs". 'n Hipotese is eerder die gevolg van 'n verkennende studie as wat dit die ondersoek lei. (Mouton \& Marais, 1989:43.)

Die volgende navorsingsaanname is gevolglik vir die studie gemaak:

As gevolg van 'n gebrek aan inligting of wanpersepsie bestaan daar 'n kennisleemte by die teikengemeenskap (Lyttelton Gemeentel gemeenskap) aangaande die aard en omvang van dienste wat deur Centurion Gemeenskapsdiens gelewer word, wat daartoe aanleiding gee dat die dienste onderbenut word.

\section{Navorsingsbenadering}

Kwalitatiewe navorsing bied 'n wyer perspektief op maatskaplike interaksie en is daarop gerig om menslike interaksie te beskryf, verstaan en te interpreteer ook in terme van die betekenis wat respondente daaraan heg (Schurink, 1998a:240).

In hierdie studie is ondersoek ingestel na die teikengroep se persepsies en behoeftes en poog die navorsers om hul optrede (motivering vir die benutting van dienste of die belewenis daarvan) te verstaan. Daarom is 'n kwalitatiewe benadering aangewese.

\section{Soort navorsing}

In enige professie is die ontwikkeling van tegnologie noodsaaklik in die bereiking van spesifieke doelwitte (De Vos, Schurink \& Strydom, 1998:9-10).

Die resultate en aanbevelings wat uit die empiriese ondersoek verkry is, is aangewend om ' $n$ effektiewe bemarkingstrategie te ontwikkel en te implementeer met die doel om die bereiking van organisasiedoelwitte te bevorder.

Evaluatiewe navorsing behels onder andere behoeftebepalings en programmonitering (De Vos, 1998:367). Ondersoek is ingestel na die teikengroep se behoeftes en verwagtinge (behoeftebepaling) van die beskikbare dienste en die mate van tevredenheid wat verbruikers ervaar. Die studie behels ook programmonitering ('n evaluatiewe element) waardeur vasgestel word of die bedoelde teikengroep deur huidige programme bereik word. Die studie behels dus 'n kombinasie van ontwikkelings- en evaluatiewe navorsing.

\section{Navorsingsontwerp}

Geen bemarkingstrategie kan effektief wees indien die behoeftes van die teikenmark nie in ag geneem is nie. In hierdie verband is nog geen wetenskaplike ondersoek ingestel nie, daarom is ' $n$ verkennende ontwerp aangewese.

Volgens Grinnell, soos aangehaal deur Fouchè en De Vos (1998:124), is die doel met 'n verkennende ontwerp om oor 'n navorsingsvraag waaroor min bekend is, te eksploreer. Die doel hiermee is om veralgemenings te weerlê en hipoteses te ontwikkel wat later verder ondersoek kan word.

\section{Navorsingsprosedure en werkwyse}

Die navorsers het van onderhoude aan die hand van 'n semi-gestruktureerde skedule as kwalitatiewe data-insamelingsmetode gebruik gemaak. Die skedule bied slegs temas wat as riglyne vir die onderhoud gedien het. Die temas is op die sewe kritiese besluitnemingsareas (sewe P's) gebaseer. 
Die populasie is alle persone wat in die tydperk 1 Junie 2001 tot 30 Mei 2002 van die dienste van Centurion Gemeenskapsdiens gebruik gemaak het en bestaan uit die volgende groepe/aktiwiteite/dienste waarby individue ingeskakel het:

- Individuele terapie

- Ouerleidinggroep

- Huweliksverrykingskursus

- Kindervakansieprogramme (ouers: verbruikers)

- Dagsorg vir babas (ouers: verbruikers)

- Goue Jare Groep (Aksie vir senior lidmate)

Uit hierdie populasie is twaalf respondente deur middel van doelgerigte steekproeftrekking verkry. Onderhoude is deur een van die navorsers self gevoer. Die proses is voorafgegaan deur sowel intensiewe bestudering van toepaslike literatuur en emosionele voorbereiding, as voorbereiding van die respondente (Schurink, 1998b:299).

\section{Data-analise}

Geraadpleegde literatuur is dit eens dat daar in kwalitatiewe navorsing nie 'n verkeerde of korrekte metode vir die analise van data is nie, maar wel algemene riglyne en verskeie strategieë.

Van die navorser word vereis om die stappe wat gevolg is, logies te verantwoord en die finale gevolgtrekkings op gegenereerde data te laat berus (Poggenpoel, 1998:337:44).

$\mathrm{Na}$ die oorweging van die benaderings wat deur verskillende navorsers voorgestaan word, het die navorsers verkies om die benadering van Tesch (1990), soos aangehaal deur Poggenpoel (1998:343-344), te volg. Die prosedure wat gevolg is, sal kortliks bespreek word:

- Die navorsers het 'n geheelbeeld verkry deur al die transkripsies versigtig deur te lees. Spesifieke idees is neergeskryf.

- Die navorsers het een onderhoud gekies, dit deurgelees en gepoog om vas te stel wat die onderliggende tema van die onderhoud is. Aantekeninge is in die kantlyn gemaak.

- Hierdie proses is ten opsigte van elkeen van die respondente herhaal en 'n lys van al die onderwerpe is daarna gemaak. Ooreenstemmende onderwerpe is saamgevoeg en in kolomme georganiseer. Dit is georganiseer in hoof onderwerpe, unieke onderwerpe en dit wat nie ingesluit is nie.

- Die navorsers het hierdie lys geneem en na die data teruggekeer. Die onderwerpe is afgekort en kodes is langs die toepaslike segmente van die teks geskryf. Die navorsers het daarna die voorlopige skema getoets om vas te stel of nuwe kategorieë en kodes na vore kom.

- Die mees beskrywende bewoording vir die onderwerpe is daarna gevind en in kategorieë omskep. Die totale lys van kategoriëe is verminder deur dit te groepeer in onderwerpe wat aan mekaar verwant is. Daar is voorts ooreenkomste tussen die kategorieë aangedui om onderlinge verwantskappe te identifiseer.

- Die navorsers het 'n finale besluit ten opsigte van die afkortings vir elke kategorie geneem en die kodes gealfabetiseer. 
- Die data wat tot elke kategorie behoort, is in een plek saamgevoeg en 'n voorlopige analise is uitgevoer.

- Die navorsers het aan bestaande data nuwe kodes waar dit nodig geag was, toegeken.

\section{Verifiëring van data}

Vier strategieë word deur Guba (1981), soos aangehaal deur Krefting (1990:215-217), voorgestel waarvolgens die betroubaarheid van kwalitatiewe navorsingsresultate beoordeel kan word. Dit behels die volgende:

\section{Waarheid}

Die geloofwaardigheid van die navorsingsbevindinge word hierdeur krities beoordeel. Dit bevestig die navorsers se vertroue in die navorsingsresultate wat gebaseer is op die navorsingsontwerp wat gebruik is, die inligting wat deur die respondente verskaf is en die konteks. Die navorsers het deurgaans die korrekte prosedure en navorsingsmetodiek gevolg.

\section{Aanwendbaarheid}

In kwalitatiewe navorsing moet vasgestel word hoe toepaslik die navorsing vir die betrokke situasie is en of dit in 'n ander soortgelyke opset gebruik kan word. Die resultate wat uit hierdie ondersoek verkry word, kan deur Centurion Gemeenskapsdiens as 'n bemarkingstrategie verder ontwikkel en onmiddellik geïmplementeer word. Met enkele aanpassings kan dit in 'n ander soortgelyke opset toegepas word.

\section{Standhoudend}

Hierdie aspek verwys na die stabiliteit en standhoudendheid van navorsingsresultate indien die ondersoek in 'n soortgelyke opset, met dieselfde respondente deur 'n ander navorsers herhaal sou word.

\section{Neutraliteit}

Die navorsing is nie die resultaat van die navorsers se vooroordele, motivering en perspektiewe nie, maar berus op die data van informante en die konteks waarbinne die navorsing uitgevoer is. In hierdie ondersoek is die onderhoude op oudio-kasette opgeneem, waarna dit woordeliks getranskribeer is. Die inligting kan dus bevestig word.

\section{BESPREKING VAN NAVORSINGSRESULTATE}

Onderhoude is met twaalf respondente gevoer. 'n Onderhoudskedule wat as riglyn vir die onderhoude gedien het, is geformuleer. Die besprekingsvrae of temas is gebaseer op die sewe kritiese besluitnemingsareas, waar daar op verbruikerstevredenheid en behoeftes gefokus is. Die skedule het die volgende vrae bevat en is tydens elke onderhoud aan die orde gestel:

TEMA EEN : (Promosie)

(Vraag 1):Hoe het u bewus geraak van die aard van dienste wat deur Centurion Gemeenskapsdiens aangebied word?

(Vraag 2): Is u van mening dat pogings om die diens in die gemeenskap bekend te stel tot op hede effektief was?

(Vraag 3): Hoe sou ons die diens beter in die gemeenskap bekend kon stel ? 
TEMA TWEE: (Plek)

Is die kantore van Centurion Gemeenskapsdiens na u mening sentraal geleë en toeganklik vir alle lede van die gemeenskap? Hoe beïnvloed die fisiese kantooropset u beeld van die diens ?

TEMA DRIE: (Professionele persone)

Hoe het die professionele persone verbonde aan Centurion Gemeenskapsdiens u beeld van die organisasie beïnvloed?

TEMA VIER: (Beeld)

Watter beeld dink u het gemeenskapslede van die organisasie? Wat gebeur hier met verwysing na die aard van die dienste wat aangebied word?

TEMA VYF: (Prys)

Is die prys wat verbruikers betaal in terme van tyd en opoffering billik in terme van die waarde wat hulle uit dienslewering verkry? Beskryf asseblief volledig.

TEMA SES: (Proses)

Het $\mathrm{u}$ die hulpverleningsproses as verbruikersvriendelik beleef?

TEMA SEWE: (Produk)

Is u van mening dat die program/dienste waarvan u gebruik gemaak het in u behoeftes voorsien en 'n verskil in u lewenskwaliteit gemaak het ?

TEMA AGT: (Verbruikers se behoeftes/ "customer needs and wants").

Drie besprekingsvrae:

- Wat is na u mening die grootste behoefte van gemeenskapslede en hoe sou Centurion Gemeenskapsdiens dit kon aanspreek?

- Wat is na u mening die grootste behoefte by die teikengroep wat u verteenwoordig en behoort in die ontwikkeling van programme aangespreek te word?

- Deur watter een sinvolle aksie/program of diens aan te bied, sou dit 'n merkbare verskil in die gemeenskap maak?

In die analisering van die data is temas (kategorieë en sub-kategorieë) onder elkeen van die sewe P's identifiseer en volgens Tesch se benadering verwerk, soos reeds beskryf. Die belangrike subtemas is vervat in die tabelle, waarvan slegs die belangrikste tabelle in hierdie artikel weergegee word.

\section{Bevindinge}

Tema een (Promosie)

\section{Besprekingsvraag 1}

Die bekendstelling van dienste was tot op hede slegs gedeeltelik suksesvol en is eensydig beleef deurdat die meeste respondente deur die gemeente daarvan bewus geraak het.

\section{Besprekingsvraag 2}

Tot dusver was pogings om die dienste bekend te stel, oneffektief. (Tabel 1.)

Hierdie tabel word weergegee omdat dit een van die doelwitte van die studie is om te bepaal wat verbruikers se persepsie van die diens is. 
TABEL 1

EFFEKTIWITEIT VAN BEKENDSTELLINGSPOGINGS

\begin{tabular}{|ll|c|}
\hline \multicolumn{2}{|c|}{ ITEM } & $\begin{array}{c}\text { PERSENTASIE } \\
\text { n=12 }\end{array}$ \\
\hline 1. & Beperkinge bestaan in die bekendstelling van dienste & $16.6 \%$ \\
\hline 1.1 & bemarking van dienste is moeilik & $8.3 \%$ \\
\hline 1.2 & mense beleef assosiasie met dienste konfronterend en vermy dit \\
\hline 2. & $\begin{array}{l}\text { Beter bekendstelling van dienste word vereis omdat gemeenskapslede steeds } \\
\text { onkundig daaroor is. }\end{array}$ & $16.6 \%$ \\
\hline 2.1 & gedeeltelik bewus van dienste & $8.3 \%$ \\
\hline 2.2 & onseker of pogings suksesvol was & $50 \%$ \\
\hline 2.3 & bekendstelling moet wyer as die gemeente gerig word & $8.3 \%$ \\
\hline 2.4 & baie wat die dienste nodig het, is nie bewus daarvan nie & $8.3 \%$ \\
\hline 2.5 & verwag meer sigbare reklame & $8.3 \%$ \\
\hline 2.6 & meer advertensie noodsaaklik & $16.6 \%$ \\
\hline 2.7 & onkundig oor ander dienste & $16.6 \%$ \\
\hline 3. & Gedeeltelike sukses is met bekendstellingspogings bereik. & $8.3 \%$ \\
\hline 3.1 & Die diens in die algemeen & $8.3 \%$ \\
\hline 3.2 & Quintots (dagsorg vir babas) & $8.3 \%$ \\
\hline 3.3 & Kinderweke & \\
\hline 4. & $\begin{array}{l}\text { Sukses van bekendstellingspogings is moeilik te bepaal weens afwesigheid } \\
\text { van spesifieke doelwitte. }\end{array}$ \\
\hline
\end{tabular}

Uit die empiriese gegewens kan afgelei word dat die teikenmark nog nie genoegsaam ingelig is oor die beskikbare dienste nie. Promosie was tot op hede om die volgende redes onsuksesvol:

- Belangstelling in die organisasie en die produk is nog nie na wense bevorder nie.

- Die voordele van beskikbare dienste is nog nie genoegsaam gekommunikeer en bekendgestel nie.

- Verbruikers is nie genoegsaam oorreed om van die diens gebruik te maak nie. (Cowell, 1991:163.)

\section{Besprekingsvraag 3}

Die inhoud van promosie (die totale boodskap) behoort meer spesifieke inhoud te bevat, deur 'n verskeidenheid van aktiwiteite en media te geskied, meer gefokus en wyer as die gemeente plaas te vind. (Vergelyk Tabel 2.) 
TABEL 2

VOORSTELLE VIR DIE BEVORDERING VAN PROMOSIE

\begin{tabular}{|c|c|c|}
\hline & ITEM & $\begin{array}{c}\text { PERSENTASIE } \\
\mathrm{n}=12\end{array}$ \\
\hline 1. & Bemark deur die aanbieding van spesifieke projekte & \\
\hline 1.1 & modeparade & $8.3 \%$ \\
\hline 1.2 & inligtingsaande & $8.3 \%$ \\
\hline 1.3 & opedag met vlooimark & $8.3 \%$ \\
\hline 2. & Bemarking moet gefokus wees en verskillende groepe bereik & \\
\hline 2.1 & potensiële verbruikers & $8.3 \%$ \\
\hline 2.2 & besluitnemers in die gemeenskap & $8.3 \%$ \\
\hline 2.3 & ander professionele persone & $25 \%$ \\
\hline 2.4 & ander gemeentes & $16.6 \%$ \\
\hline 3. & $\begin{array}{l}\text { Bekendstelling van spesifieke dienste en projekte waarby CGD betrokke } \\
\text { is }\end{array}$ & $16.6 \%$ \\
\hline 4. & Bemark deur ander organisasies & \\
\hline 4.1 & skole & $8.3 \%$ \\
\hline 4.1 .1 & terapeutiese dienste: inligtingstuk & $8.3 \%$ \\
\hline 4.1 .2 & skool se advertensieblad & $8.3 \%$ \\
\hline 4.1 .3 & onderhoude met spesifieke personeellede & $8.3 \%$ \\
\hline 5. & Benut media-beriggewing & \\
\hline 5.1 & koerante/ dagblaaie/ Rekord (plaaslike koerant) en Beeld & $75 \%$ \\
\hline 5.2 & radio & $8.3 \%$ \\
\hline 5.3 & tydskrifartikels & $8.3 \%$ \\
\hline 6. & 'n Verskeidenheid van bemarkingsinstrumente & \\
\hline 6.1 & inligtingsborde met algemene en spesifieke inligting & $8.3 \%$ \\
\hline 6.2 & plakkate & $8.3 \%$ \\
\hline 6.3 & pamflette & $16.6 \%$ \\
\hline
\end{tabular}

Die voorafgaande uitsprake bevestig dat pogings tot promosie van dienste nog nie die teikenmark effektief bereik het nie. Verskeie kreatiewe voorstelle wat in Tabel 2 vervat is, is in hierdie verband deur respondente aangebied.

Tema Twee: Plek

Die fisiese fasiliteite is sentraal geleë, doelmatig en die algemene indruk is positief. Die fasiliteite is sigbaar, toeganklik en uitnodigend. Bepaalde leemtes wat verbruikers negatief kan beïnvloed, bestaan wel en moet dringend aangespreek word.

Tema Drie: Professionele Persone

Die professionele personeel beïnvloed die verbruikers se beeld van die organisasie positief en boesem vertroue in. Dienste is onsigbaar en die sigbare personeel is die enigste konkrete aanduiding van die aard of kwaliteit van die diens. Personeel moet in hul kontak met die publiek hierop ingestel wees. 
Tema Vier: Beeld

Potensiële verbruikers (gemeente- en gemeenskapslede) is oningelig oor die aard van beskikbare hulp (wie by dienslewering kan baat/ verskeidenheid van dienste) en wie die teikenbevolking is. Vergelyk Tabel 3 vir volledige inligting.

TABEL 3

DIE TEIKENMARK SE INDRUK/BEELD VAN DIE DIENS.

\begin{tabular}{|c|c|}
\hline ITEM & $\begin{array}{l}\text { PERSENTASIE } \\
n=12\end{array}$ \\
\hline Gemeenskapslede is onkundig oor die aard van beskikbare hulp (dienste) & $66.6 \%$ \\
\hline 2. Onduidelik wie die ontvangers van dienste is (verwys na aard van dienste) & $16.6 \%$ \\
\hline $\begin{array}{l}\text { 3. Term "gemeenskapsdiens" of "gemeenskapsentrum" is nie beskrywend } \\
\text { genoeg nie }\end{array}$ & $16.6 \%$ \\
\hline 4. Persepsie dat dienslewering tot die gemeente beperk is & $33.3 \%$ \\
\hline 5. Selfs gemeentelede is onkundig oor die omvang van dienslewering & $8.3 \%$ \\
\hline 6. CGD slegs bekend vir die aanbieding van die kinderweke & $16.6 \%$ \\
\hline 7. Begryp eers aard van diens na benutting daarvan & $16.6 \%$ \\
\hline $\begin{array}{l}\text { 8. Onbewus dat maatskaplike funksionering bevorder word (doel met } \\
\text { dienslewering is onduidelik) }\end{array}$ & $16.6 \%$ \\
\hline
\end{tabular}

Potensiële verbruikers het dus nie 'n positiewe beeld van die organisasie nie omdat hulle nie weet watter persoonlike waarde dit vir hulle kan inhou nie.

Tema Vyf: Prys

Verbruikers beleef die monetêre en nie-monetêre prys (opoffering en blootstelling) verbonde aan dienslewering billik teenoor die waarde wat dit vir hulle inhou. Die prys van blootstelling moet egter deurentyd verreken word. Hoewel gratis dienste enersyds verwelkom word, bejeën ander verbruikers dit met skeptisisme. (Tabel 4.)

TABEL 4

DIE PRYS VIR DIENSTE: VERBRUIKERS SE MENING

\begin{tabular}{|c|c|}
\hline ITEM & $\begin{array}{c}\begin{array}{c}\text { PERSENTASIE } \\
\mathrm{n}=12\end{array} \\
\end{array}$ \\
\hline $\begin{array}{l}\text { 1. Monetêre prys verbonde aan dienslewering is billik (fooie word gehef vir } \\
\text { inskakeling by projekte en privaat terapeute). }\end{array}$ & $75 \%$ \\
\hline 2. Nie-monetêre prys & \\
\hline $\begin{array}{l}\text { 2.1 Die waarde wat die program/projek vir verbruiker inhou, regverdig die prys in } \\
\text { terme van tyd, opoffering en reiskoste. }\end{array}$ & $83.3 \%$ \\
\hline 2.2 Die prys van blootstelling is te hoog. & $8.3 \%$ \\
\hline 3. Gratis dienste & \\
\hline 3.1 Die beskikbaarheid van gratis dienste ontlok skeptisisme. & $33.3 \%$ \\
\hline 3.2 Gratis dienste word verwelkom en waardeer. & $33.3 \%$ \\
\hline 3.3 Verbruikers van dienste behoort 'n teenprestasie te lewer. & $16.6 \%$ \\
\hline 3.4 Die persepsie bestaan dat maatskaplikewerk-dienste gratis behoort te wees. & $8.3 \%$ \\
\hline
\end{tabular}


Tema Ses: Proses

Die hulpverleningsproses is deurgaans as verbruikersvriendelik ervaar, hoewel enkele leemtes wat deur verbruikers aangedui is, aangespreek moet word. (Vir volledige besonderhede vergelyk Tabel 5.)

TABEL 5

VERBRUIKERS SE ERVARING VAN DIE HULPVERLENINGSPROSES

\begin{tabular}{|c|c|}
\hline ITEM & $\begin{array}{c}\text { PERSENTASIE } \\
\mathrm{n}=12\end{array}$ \\
\hline 1. Alle hulpverleningsprosesse is as verbruikersvriendelik beleef. & $75 \%$ \\
\hline $\begin{array}{l}\text { 2. Bekendheid met professionele personeel kan moontlik objektiewe beoordeling } \\
\text { van die hulpverleningsproses in terme van verbruikersvriendelikheid beïnvloed. }\end{array}$ & $8.3 \%$ \\
\hline 3. Oneffektiewe kommunikasie belemmer die hulpverleningsproses. & \\
\hline 3.1 Wanpersepsie dat huweliksverryking met probleme verband hou. & $8.3 \%$ \\
\hline 3.2 Behoefte aan deurlopend meer inligting aan Quintots-ouers. & $8.3 \%$ \\
\hline $\begin{array}{l}\text { 3.3 Ouers onkundig oor verloop/afwisseling van programaktiwiteite tydens } \\
\text { kinderweke. }\end{array}$ & $8.3 \%$ \\
\hline 3.4 Verbeterde koördinering met skole in die verspreiding van kinderweekpamflette. & $8.3 \%$ \\
\hline
\end{tabular}

Onvoldoende inligting kan verbruikers se beeld van dienste negatief beïnvloed, veral omdat dit 'n tipe diens is wat verbruikers met skeptisisme bejeën of nie graag mee wil assosieer nie.

Tema sewe: Beeld

Verbruikers se behoeftes is deurgaans aangespreek en hul lewenskwaliteit bevorder deur die benutting van dienste of die inskakeling by programaktiwiteite. Verskillende leemtes in dienslewering, wat met ondoeltreffende kommunikasie verband hou, is geïdentifiseer. Hierdie verbruikers se behoeftes is slegs gedeeltelik aangespreek en die oplossing of bevrediging daarvan is ook slegs gedeeltelik. Die produk moet die presiese behoeftes van verbruikers aanspreek en is in daardie spesifieke sin probleemoplossend (Hannagan, 1992:102).

Tema Agt: Verbruikers se behoeftes

Verbruikers se behoeftes vorm die kern van 'n markgerigte benadering.

Behoeftes wat deur respondente geïdentifiseer is, is uiteenlopend, maar sentreer veral rondom huweliks- en gesinsaangeleenthede en finansiële druk. Pessimisme oor die toekoms, eensaamheid, chemiese- en alkoholafhanklikheid word ook deur 'n aantal respondente as behoeftes aangedui. Die hantering van lewenseise verg 'n verskeidenheid van vaardighede wat tans ontbreek.

Benewens die verskeidenheid van behoeftes het respondente versoek dat:

Centurion Gemeenskapsdiens 'n plek moet wees waar mense in privaatheid ondersteun kan word in die hantering van lewenseise en -krisisse en dat die beskikbaarheid van bestaande dienste beter bekendgestel word.

In plaas van algemene behoeftes aan te spreek, kan organisasies volgens Kotler en Andreasen (1991:167) tussen die verskillende voorgestelde segmente onderskei, elke segment evalueer, teikenmarkte identifiseer en dienste wat op die behoeftes van elkeen afgestem is, ontwikkel. Segmentasie verseker dat verbruikers die beste by dienste kan baat deurdat daar binne 'n spesifieke veld van kundigheid op sterk punte in die organisasie gefokus word. 
Die volgende prioriteite kan vir toekomstige programbeplanning oorweeg word:

- Toenemende eise en finansiële druk : finansiële begeleiding/ bejaardes se finansies/ ondersteuning in werksonsekerheid, werkloosheid en armoede.

- Huweliks- en gesinsaangeleenthede: huweliksprobleme/ gesinsverbrokkeling (nie egskeiding nie)/ egskeidingsbegeleiding/emosionele verwerking van egskeidingsverwante trauma by kinders deur spelterapie/ naskoolsentrum met beter toesig en minder kinders/ vermaaklikheid vir jeug/ beskikbaarheid van kursusse in studiemetodes

- Effektiewe ouerleiding: ouers met jong kinders en tieners/ouers van kinders met spesiale behoeftes

- Enkelouers: ondersteuning aan ouers met jong kinders/ ondersteuningsgroepe om die behoeftes van die weduwees en wewenaars aan te spreek en vir vroue wat pas geskei is om sosialisering te bevorder

- Werkende moeders met jong kinders: ondersteuning en hantering van skuldgevoelens / kindervakansie-programme met voldagtoesig (dagsorg vir babas kan hierby ingesluit word)

- Vereensaming en onbetrokkenheid veral ten opsigte van bejaardes: meer programme en aanbiedings- meer aktiewe deelname om passiwiteit teen te werk / behoefte om sin in die lewe te ervaar

- Terapeutiese dienste: behoefte aan 'n terapeut wat nie persoonlik aan die verbruikers bekend is nie

- Bestuur van en aanpassing by verandering (veral in die middeljare- in 'n samelewing sonder enige materiële sekuriteit)

- Hantering van stres: (bekommernis en pessimisme oor die toekoms) - gebrek aan lewensvaardighede om dit te hanteer

- Chemiese en alkoholafhanklikheid: ondersteuning aan gesinslede

Een van die doelwitte wat vir die uitvoering van die studie gestel is, is dat die aanbevelings wat uit die ondersoek verkry word, benut word in die ontwikkeling van 'n verbruikersgerigte bemarkingstrategie. Riglyne vir die ontwikkeling van 'n bemarkingstrategie word vervolgens weergegee:

\section{AANBEVELINGS EN RIGLYNE VIR DIE ONTWIKKELING VAN 'N BEMARKINGSTRATEGIE}

Uit bestudeerde literatuur is dit duidelik dat 'n bemarkingstrategie uit die implementering van die totale strategiese bemarkingsbeplanningsproses ontwikkel (Hannagan, 1992:46; Jooste, 2001:360; Lovelock, 1991:387).

Die volgende aanbevelings is gegrond op inligting soos verkry uit die empiriese ondersoek en literatuurstudie:

- Die strategiese beplanningsproses moet geïmplementeer word sodat onder andere duidelikheid oor die organisasie se missie en doelstellings verkry word. 
- Die bemarkingsbeplanningsproses (wat die strategiese analise, die SWOT-analise, bemarkingsdoelwitte en markstrategie behels en nou verweef is met die strategiese beplanningsproses) moet volledig uitgevoer word.

- Die volgende aanbevelings ten opsigte van die kritiese besluitnemingsareas (sewe P's) moet geïmplementeer word:

\section{Promosie}

- Daar kan voortgegaan word met huidige bekendstellingspogings, maar beskikbare dienste moet ook buite die NG Kerk-verband bekendgestel word. Gemeentes se advertensieblaaie of nuusbriewe kan hiervoor benut word.

- Die beskikbare dienste moet deur die aanbieding van spesifieke projekte of geleenthede soos 'n modeparade, inligtingsaand of 'n opedag bekendgestel word.

- Bemarking moet gefokus wees om ander potensiële verbruikers (behoeftes van spesifieke teikenmarkte), besluitnemers en professionele persone soos byvoorbeeld sielkundiges, arbeidsterapeute en medici te bereik.

- Die betrokkenheid van Centurion Gemeenskapsdiens by bestaande projekte, byvoorbeeld dagsorg vir babas, kinderweke, die huwelikskursus of ouerleidingskursus moet spesifiek aangedui word, aangesien potensiële verbruikers nie noodwendig daarvan bewus is dat sodanige dienste deur Centurion Gemeenskapsdiens aangebied word nie.

- Media-beriggewing moet meer effektief en doelgerig benut word, byvoorbeeld die dagblad (Beeld) en die area-koerant (Centurion Rekord) vir weeklikse of minstens maandelikse berigte en mededelings in verband met programme en beskikbare dienste.

- Dienste moet deur e-pos, pamflette, plakkate en die benutting van die inligtingsborde voor die kantore bekendgestel word. Die bewoording op die inligtingsborde moet gewysig word om verbruikers se behoeftes aan te spreek. Die verskeidenheid van beskikbare dienste moet duideliker uitgespel word. Belangrike datums en spesifieke geleenthede moet aangedui kan word.

- Promosieverwante aktiwiteite moet deel van die jaarbeplanning vorm, wat spesifieke korttermyndoelwitte en aktiwiteite vir elke maand insluit en waardeur deurlopende bemarking verseker sal word.

- Die unieke aard van dienste moet in die uitvoering van promosieverwante aktiwiteite verreken word. Omdat dienste nie tasbaar is nie, moet vertroue ingeboesem word deur die voordele van die beskikbare dienste vir die verbruikers uit te spel. Die teikenmark moet beter ingelig wees oor die wyses waarop hulle persoonlik by dienste kan baat.

- Daar moet nouer skakeling met skole plaasvind. Inligting oor alle dienste (nie net kinderweke nie, maar ook terapeutiese dienste) moet skole minstens tweemaandeliks bereik. Persoonlike kontak moet by herhaling met spesifieke sleutelfigure (onderwysers) gemaak word om vertroue in te boesem. Die skool se advertensieblad of 'n spesifieke brosjure kan hiervoor gebruik word.

\section{Plek}

- Die opknapping van die geboue en terrein is noodsaaklik. Die kantore kan 'n opvallende kleur geverf word sodat die sigbaarheid daarvan verhoog word. 
- 'n Meer professionele en 'n warmer atmosfeer moet in die kantore en ontvangslokaal geskep word om verbruikers op hul gemak te laat voel. Dit word aanbeveel dat kundige advies hieroor ingewin word.

- In die ontvangslokaal moet die privaatheid van kliënte ten alle koste beskerm word om blootstelling te beperk. Omdat daar leemtes in die doelmatigheid van die plek bestaan, moet personeellede, veral by die ontvangslokaal, bewus wees daarvan en meer moeite doen om verbruikers warmte te laat ervaar en tuis te laat voel.

- Daar moet ook deurentyd toegesien word dat die voorkoms en algemene indruk van fasiliteite, soos in die bewaarskool, bydra om 'n positiewe beeld te skep.

\section{Professionele persone}

- Personeel moet deurlopend gemotiveer, toegerus en in staat gestel word om so effektief moontlik te funksioneer om sodoende verbruikers se beeld van die organisasie positief te beïnvloed en vertroue in te boesem.

- Deurlopende erkenning aan personeel vir hul aandeel in die suksesvolle uitvoering van die organisasie se werksaamhede is noodsaaklik.

- Terugvoer moet aan personeel gegee word oor die mate van tevredenheid wat verbruikers ervaar. Terselfdertyd moet personeel bewus wees dat hulle verbruikers se beeld van die organisasie positief kan beïnvloed.

- Personeel behoort volgens hul vaardighede en kwaliteite binne die organisasie geselekteer, aangewend en gemonitor te word, ook in hul kontak met die publiek (veral ook by ontvangslokaal). Die waarde van al die supervisie-funksies is hierin onontbeerlik.

- Interne kommunikasie moet bevorder word sodat alle personeel ingelig is oor werksprosedures, gebeure en projekte om dadelik die korrekte en volledige inligting op navraag aan die publiek te verskaf.

- Personeel moet medeverantwoordelikheid vir die nastrewing van die missie en visie en organisasiedoelwitte aanvaar en meewerk om die bereiking van doelwitte met insette vanuit die gemeenskap te bevorder.

- Vrywilligers behoort 'n groter rol in die bestuur en werksaamhede van Centurion Gemeenskapsdiens te vervul om die missie en doelstellings te bevorder. Groter gemeenskapsbetrokkenheid moet nagestreef word en langtermynverhoudinge moet met vrywilligers opgebou word.

- Die potensiële verbruikers kan moontlik persoonlik bekend wees aan die professionele personeel. Konfidensialiteit en die beskerming van privaatheid moet daarom hoogste prioriteit wees.

\section{Beeld}

- Die term "Gemeenskapsdiens" of "Gemeenskapsentrum" is nie beskrywend genoeg nie. Die verandering van die naam van die diens moet oorweeg word om meer beskrywend te wees in terme van die aard en omvang van die dienste wat gelewer word.

- Die verskeidenheid van die dienste (op watter tipe problematiek dienslewering fokus) en die beskikbaarheid daarvan moet duideliker in die gemeenskap gekommunikeer word. 
- Die doel met 'n markgerigte benadering is om dienste wat verbruikers se behoeftes aanspreek, aan te bied (Cowell, 1991:43). Indien verbruikers nie bewus is van beskikbare dienste, kan hulle nie ' $n$ beeld of indruk vorm wat hulle positief kan beïnvloed om van die dienste gebruik te maak nie.

\section{Prys}

- 'n Teenprestasie kan deur verbruikers gelewer word vir die dienste wat hulle ontvang. Die implementering van 'n fooiestruktuur op 'n glyskaalbasis kan oorweeg word. Dit moet egter met sensitiwiteit oorweeg word. Mededinging met ander dienslewerende organisasies en die vermoë van die verbruikers om vir dienste te betaal, moet deurentyd verreken word.

- Die uitgawes verbonde aan projekte, behoort soos in die verlede, deur die verkryging van borgskappe beperk te word. Aksiekomitees vir projekte kan uitgebou word om groter inspraak en eienaarskap deur gemeenskapslede te verseker.

\section{Proses}

- Die doel met 'n projek, die beoogde teikengroep en alle relevante inligting moet in die bekendstelling van projekte ondubbelsinnig gekommunikeer word om verbruikers se spesifieke behoeftes aan te spreek en om onduidelikhede uit te skakel.

- 'n Maandelikse geleentheid vir persoonlike kontak met nuwe ouers by die dagsorgsentrum vir babas kan meehelp om onsekerhede uit te klaar. Inligting aangaande praktiese aangeleenthede en prosedures kan deur gereelde omsendskrywes en tweemaandelikse ouervergaderings aangevul word.

- In die bemarking van kinderweke moet bemarkingsaksies opgevolg word om vas te stel of die briewe soos ooreengekom, deur die skole versprei is.

- Tydens kinderweke moet ouers deurlopend oor daaglikse programaktiwiteite ingelig wees deur plakkate met die dagprogram daarop aan te bring.

- Verbruikerstevredenheid moet deurlopend tydens kinderweke gemonitor en terugvoer van ouers gevra word. Benewens die evaluering aan die einde van die week, kan 'n daaglikse geleentheid vir terugvoer geskep word.

- Monitor deurlopend die effektiwiteit van prosedures waaraan alle verbruikers van dienste blootgestel word.

\section{Produk}

- Professionele personeel moet hulself deurlopend vergewis van verbruikers se individuele behoeftes en verwagtinge sodat dit in dienslewering aangespreek kan word.

- In die bemarking van die ouerverrykingskursus moet aangedui word wie die teikenmark is en dat die kursus nie net op enkelouergesinne gerig is nie.

- Die studiemetode-kursus moet 'n opvolgkursus insluit om maksimale resultate te verseker.

- In die beplanning van die kinderweek moet ouers medeverantwoordelikheid vir die bestuur van die begroting aanvaar. Dit sal onrealistiese eise en verwagtinge in verband met die finansies voorkom. 


\section{SAMEVATTING}

In hierdie studie is ondersoek ingestel na verbruikers se kennis en belewenis van dienslewering deur Centurion Gemeenskapsdiens in terme van die sewe kritiese besluitnemingsareas. Verbruikers se behoeftes vorm die kern van 'n verbruikersgerigte benadering. Programontwikkeling moet die behoeftes van die verbruikers aanspreek en bemarking moet gedoen word sodat die teikenmark weet hoe hulle persoonlik by dienste kan baat.

'n Effektiewe bemarkingstrategie is binne die raamwerk van die strategiese bemarkingsbeplanningsproses in die organisasie ontwikkel. Dienste kan slegs optimaal benut word indien programme die behoeftes van die teikenmark effektief aanspreek en die teikenmark bewus is van die beskikbaarheid daarvan.

Die doelwitte en doelstelling wat vir die studie gestel is, is bereik. Die navorsingsvraag of aanname is bevestig, naamlik dat daar as gevolg van 'n gebrek aan inligting of wanpersepsie 'n kennisleemte by die teikengemeenskap (Lyttelton Gemeente/gemeenskap) bestaan aangaande die dienste wat deur Centurion Gemeenskapsdiens gelewer word. Dit gee daartoe aanleiding dat die dienste onderbenut word.

'n Effektiewe bemarkingstrategie is daarom noodsaaklik om diegene wat dit die nodigste het, te bereik.

\section{BIBLIOGRAFIE}

ANDREASEN, A.R. 1997. Challenges for the science and practice of social marketing. In: GOLDBERG, M.E.; FISHBEIN, M. \& MIDDLESTADT, S.E. (eds) 1997. Social marketing theoretical and practical perspectives. New Jersey: Lawrence Erobaum Associates, Publishers.

COWELL, D. 1991. The marketing of services. Oxford: Butterworth-Heinemann Ltd.

CROMPTON, J.L. \& LAMB, C.W., (Jr) 1986. Marketing government and social services. Canada: John Wiley \& Sons, Inc.

DE VOS, A.S. 1998. Programme evaluation. In: DE VOS, A.S. (ed) 1998. Research at grass roots: a primer for the caring professions. Pretoria: Van Schaik.

DE VOS, A.S.; SCHURINK, E.M. \& STRYDOM, H. 1998. The nature of research in the caring professions. In: DE VOS, A.S. (ed) 1998. Research at grass roots: a primer for the caring professions. Pretoria: Van Schaik.

FOUCHE, C.B. \& DE VOS, A.S. 1998. Selection of a research design. In: DE VOS, A.S. (ed) 1998. Research at grass roots: a primer for the caring professions. Pretoria: Van Schaik.

HANNAGAN, T.J. 1992. Marketing for the non-profit sector. Hampshire: The MacMillan Press Ltd.

HERBST, F. 2001. Strategic management of marketing value-mix variables. In: DU PLESSIS, P.J., JOOSTE, C.J. \& STRYDOM, J.W. (reds) Applied strategic marketing. Sandown: Heinemann Publishers (Pty) Ltd.

JOOSTE, S. 1993. Toepassingsgebiede in bemarking. In: MARX, S. \& VAN DER WALT, A. (reds) Bemarkingsbestuur. (2de uitg) Kaapstad: Juta en Kie Bpk.

JOOSTE, C.J. 2001. Strategic marketing planning. In: DU PLESSIS, P.J.; JOOSTE, C.J. \& STRYDOM, J.W. (reds) Applied strategic marketing. Sandown: Heinemann Publishers (Pty) Ltd. 
KOTLER, P. \& ANDREASEN, A.R. 1991. Strategic marketing for nonprofit organizations. $\left(4^{\text {th }}\right.$ ed) Englewood Cliffs, New Jersey: Prentice-Hall, Inc.

KREFTING, L. 1990. Rigor in qualitative research: The assessment of trustworthiness. American Journal of Occupational Therapy, 45(3):214-222.

KURTZ, D.L. \& CLOW, K.E. 1998. Services marketing. New York: John Wiley \& Sons.

LOVELOCK, C.H. 1991. Services marketing. ( $2^{\text {nd }}$ ed) Englewood Cliffs, New Jersey: Prentice Hall.

MAYERS, R.S.1989. Financial management for nonprofit human service agencies. Illinois: Charles Thomas Publisher.

MOUTON, J. \& MARAIS, H.C. 1989. Metodologie van die Geesteswetenskappe: basiese begrippe. Pretoria: Raad vir Geesteswetenskaplike Navorsing.

POGGENPOEL, M. 1998. Data analysis in qualitative research. In De Vos, A.S. (Ed) 1998. Research at grass roots: a Primer for the caring professions. Pretoria: Van Schaik.

SCHURINK, E.M. 1998a. Deciding to use a qualitative research approach. In: DE VOS, A.S. (ed) 1998. Research at grass roots: a primer for the caring professions. Pretoria: Van Schaik.

SCHURINK, E.M. 1998b. The methodology of unstructured face-to-face interviewing. In: DE VOS, A.S. (ed) 1998. Research at grass roots: a primer for the caring professions. Pretoria: Van Schaik.

WEYERS, M.L. 1999. The nature and application of Social Marketing: A community work perspective. Social Work/Maatskaplike Werk, 35(2):124-131.

WOLF, T. 1990. Managing a nonprofit organization. New York: Prentice Hall Press. 